\title{
Proliferating Brenner tumour
}

\author{
M. BARATZ \\ M.D. \\ M. P. DAVID \\ M.D.
}

\author{
S. Z. GITSTEIN \\ M.D.
}

A. AVNI

M.D.

\begin{abstract}
Dept of Pathology, Ichilov Hospital, Dept of Gynecology and Obstetrics B, Hakiria Hospital, Tel-Aviv, Sackler Medical School, University of Tel-Aviv
\end{abstract}

\begin{abstract}
Summary
A new case of proliferating Brenner tumour is added to the 18 previously reported cases, and the literature relating to this particular kind of tumour is reviewed.

\section{Introduction}

The following case of a proliferating Brenner tumour represents the nineteenth report in the literature (Miles and Norris, 1972; Roth and Sternberg, 1971; Chang, Roberts and Homesley, 1977; Hallgrimsson and Scully, 1972). It is important to recognize this intermediate proliferative variety, as it may easily be confused with a malignant Brenner tumour.
\end{abstract}

\section{Case report}

A 62-year-old white female, nulligravida, 10 years post-menopause, was admitted to hospital because of a low abdominal mass discovered upon routine gynaecological examination. Physical examination on admission was unremarkable except for the presence of a movable mass located in the left lower abdomen. At exploratory laparotomy, a left ovarian tumour was discovered and total abdominal hysterectomy with bilateral salpingo-oöphorectomy was performed. The postoperative course was satisfactory and the patient was discharged on the 7th day.

\section{Pathological findings}

The left ovary was replaced by an ovoid mass that measured $11 \times 7 \times 4 \mathrm{~cm}$. The external surface was bosselated, grey-white and glistening. The fallopian tube was attached to the mass in one area. The bisected specimen was partially cystic and partially solid (Fig. 1). The cystic area was multilocular with large and small cystic spaces containing watery to

Reprints from: Dr M. Baratz, Institute of Pathology, Tel-Aviv Medical Center, Ichilov Hospital, 6 Weizman Street, Tel-Aviv, Israel. slightly mucoid fluid. The largest cyst measured $4 \mathrm{~cm}$ in diameter, thickness of wall $0.1 \mathrm{~cm}$. The solid portion showed 2 distinct areas: at the periphery a hard, whitish-yellow, gritty homogeneous tissue and a large soft papillary mass growing into the cystic spaces (Fig. 2). The right ovary and both fallopian tubes were normal. Microscopically the peripheral solid area was typical of the Brenner tumour and consisted of islands of squamoid or transitional-like epithelial cells with varying density of intervening stroma and many calcifications disposed in the epithelial nests and in the stroma (Fig. 3). In the soft papillary intracystic growth the Brenner epithelium assumed a papillary appearance and consisted of 10-20 layers of epithelial cells, which generally maintained their uniform appearance (Fig. 4). There was focal atypism consisting of hyperchromatic cells, but none of the epithelial areas had cytological characteristics of malignancy and no stromal invasion was seen. The lesion resembled a low-grade papillary transitional cell carcinoma of the urinary bladder. Throughout the tumour was a mucinous transformation of epithelial cells, resulting in small to larger cavities of varying sizes, containing a mucicarmine and periodic acid Schiff-positive material. Elsewhere the cyst lining was smooth and composed of mucinous epithelium and partially of transitional epithelium.

\section{Discussion}

Meyer (1932) introduced the term Brenner tumour for the ovarian neoplasm, which was first described by Brenner (1907). Since its first description this tumour has been the subject of numerous papers attempting to establish its histogenesis and endocrine activity. The structure of these tumours is characterized by the presence of epithelial cell foci or columns distributed within a prominent fibrous stroma. These cells show remarkable uniformity and tendency for mucinous transformation. Although 


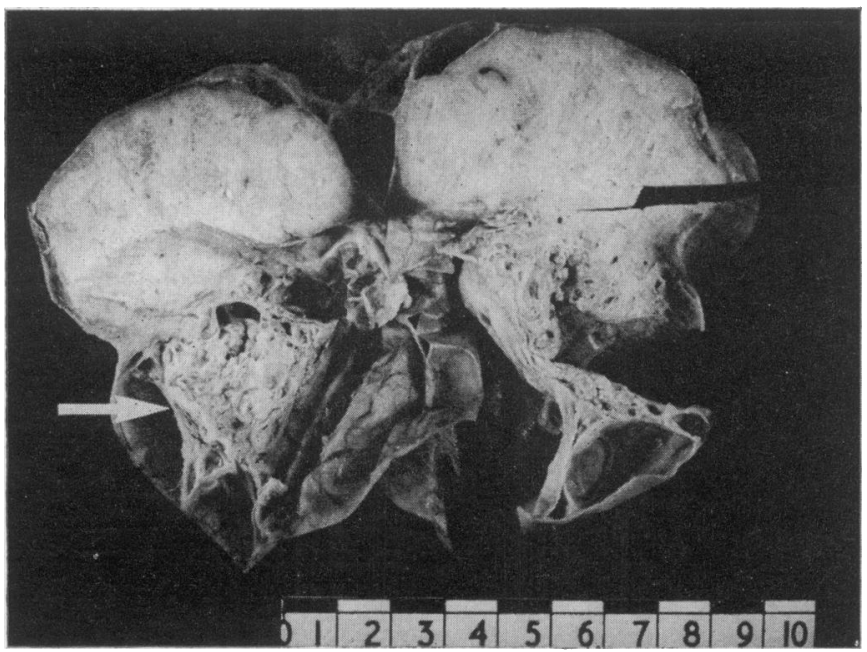

FIG. 1. The bisected specimen shows a hard whitish homogeneous tissue in the upper region and cystic spaces variable in size in the lower part. A large soft papillary mass grows into the cystic spaces (arrow).

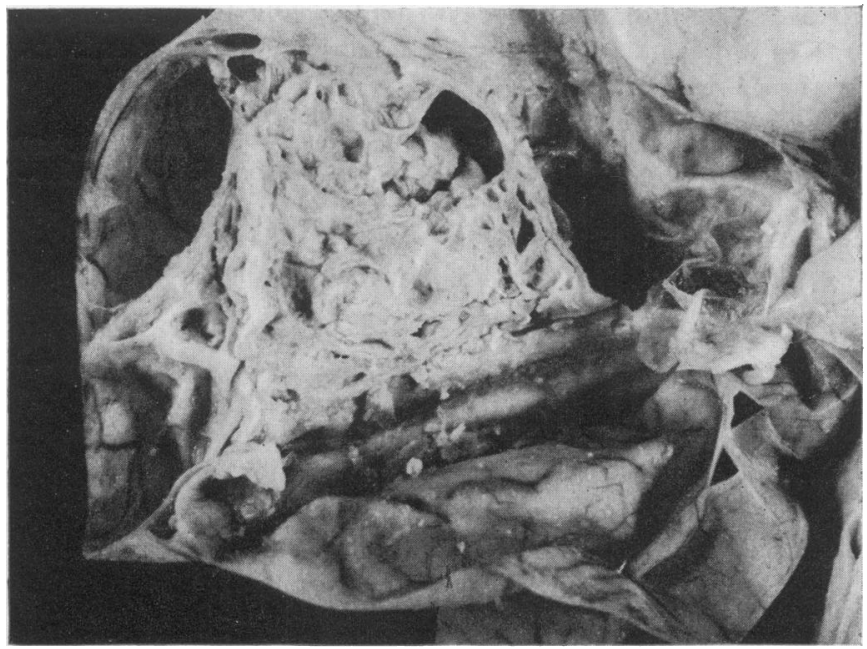

FIG. 2. Higher magnification of the soft papillary mass growing into the cystic spaces.

characteristically benign, about 42 malignant Brenner tumours have been reported (Miles and Norris, 1972).

Roth and Sternberg (1971) described an unusual form of Brenner tumour - an intermediate neoplasm between the usual benign Brenner tumour and its frankly malignant counterpart, and called it 'proliferating Brenner tumour'. The proliferating Brenner tumour is characterized by an unusual degree of proliferation of Brenner epithelium resembling lowgrade papillary transitional cell carcinoma of the urinary bladder.

Lack of cellular atypism, mitosis and stromal invasion are the criteria which differentiate this entity from the malignant counterpart (Roth and Sternberg, 1971). Generalization concerning this variety of Brenner tumour is difficult, because of the small number of reported cases. They are generally 


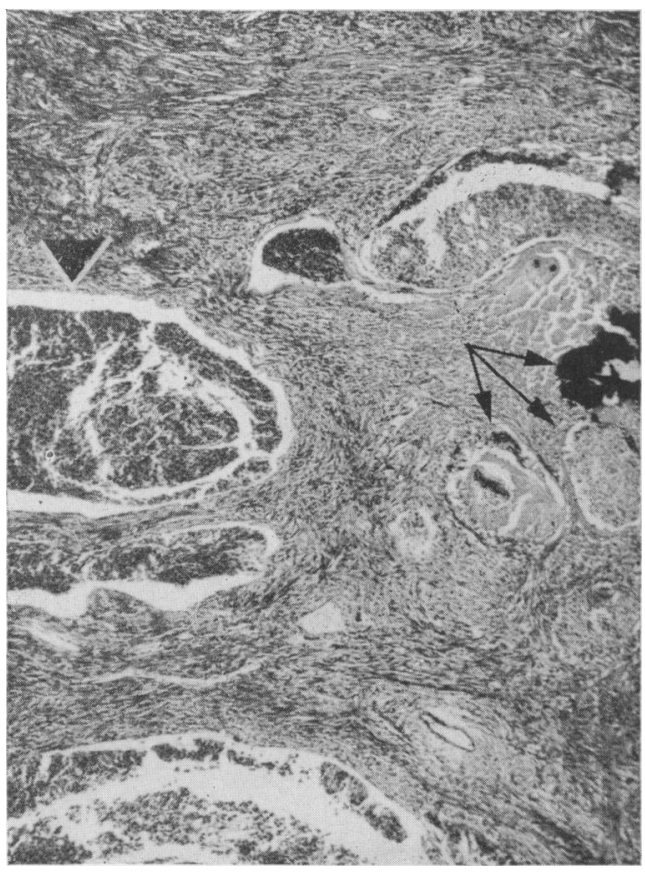

FIG. 3. Islands of epithelial nests and calcifications disposed in a fibrous stroma typical for Brenner tumour (arrows) and foci showing an unusual degree of epithelial proliferation (arrow heads) (HE, $\times 60)$. large, mixed cystic and solid tumours. The characteristic macroscopic feature is the presence of soft papillary masses growing into cystic spaces, as is well illustrated in the present case. The presence of Sudanophile (or lipid) granules in the stromal and epithelial cells has been considered as histological evidence of the hormonal activity of Brenner tumours (Ming and Goldmann, 1962).

Proliferating Brenner tumour may cause postmenopausal bleeding owing to endometrial hyperplasia, but the presenting symptom may be an abdominal mass without other clinical complaints. In the present case, lipid stains were negative and there was no clinical or pathological support for endocrine activity. There is still no complete agreement as to the histogenesis of Brenner tumour. The appearance of the proliferating Brenner tumour resembling low-grade papillary transitional cell carcinoma of the urinary bladder, gives additional support to the concept that it originates from the coelomic epithelium, which is capable of transitional (urothelial) and mucinous (uterino-cervical) differentiation, both of which are also characteristics of Brenner tumours. Proliferating Brenner tumour is biologically benign and the resection of the ovary containing the tumour is the treatment of choice.

References

BRENNER, F. (1907) Das Oöphoroma folliculare. Frankfurte $\frac{0}{6}$ Zeitschrift für Pathologie, 1, 150.

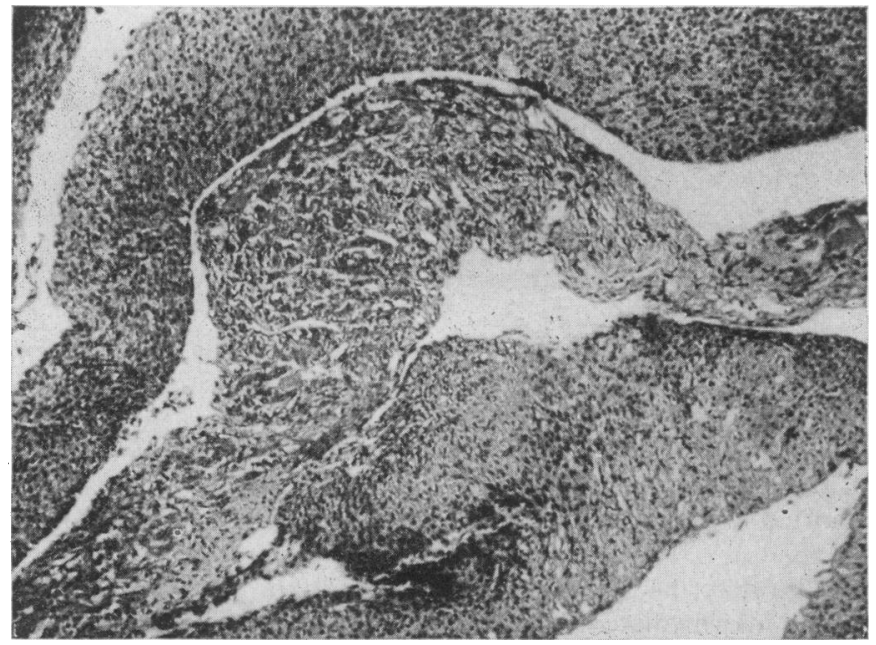

Fig. 4. Papillary structures lined by 10-20 layers of uniform epithelial cells resembling a low-grade papillary transitional cell carcinoma, characteristic for proliferating Brenner tumour $(\mathrm{HE}, \times 200)$. 
Chang, S.H., Roberts, J.M. \& Homesly, H.D. (1977) Proliferating Brenner tumor. Obstetrics and Gynecology, 49, 489.

Hallgrimsson, J. \& Scully, R. (1972) Borderline and malignant Brenner tumors of the ovary. Acta pathologica microbiologica scandinavica, 80 (Suppl. 233), 56.

MEYER, R. (1932) Der Tumor ovarij Brenner, eine besondere Art von Geschwulst und ihre Stellung unter den Geschwülsten des Eierstocks. Zentralblatt für Gynäkologie, 56, 770.
Miles, A.Ph. \& Norris, H.J. (1972) Proliferative and malignant Brenner tumors of the ovary. Cancer, New York, Philadelphia, etc., 30, 174.

Ming, S.C. \& Goldman, H. (1962) Hormonal activity of Brenner tumors in postmenopausal women. American Journal of Obstetrics and Gynecology, 83, 666.

Roth, L.M. \& Sternberg, W.H. (1971) Proliferating Brenner tumor. Cancer, New York, Philadelphia, etc., $27,687$. 